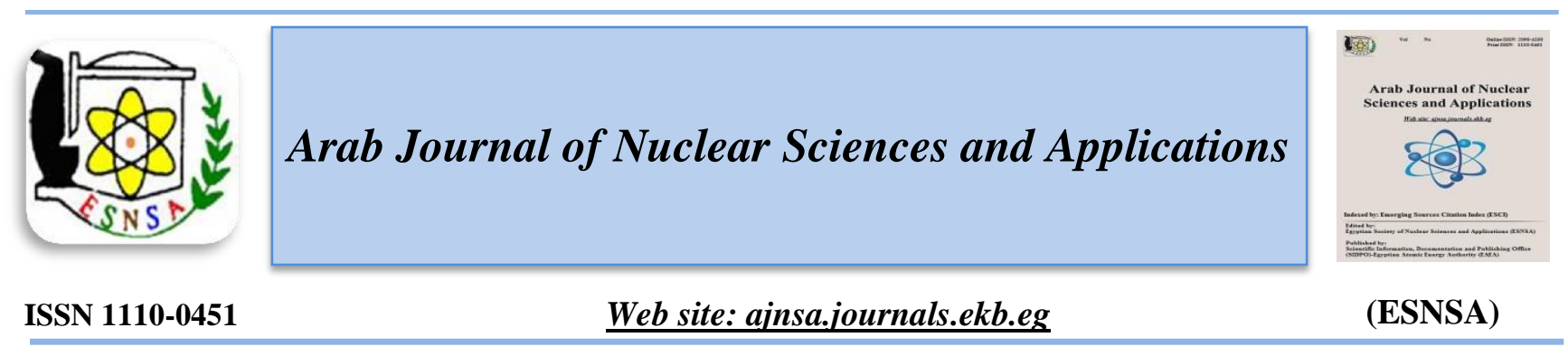

\title{
A Road Map for Nuclear Knowledge Management Program for a Regulatory Body
}

\author{
R.I. Gomaa, Karim El-Adham \\ QC/QA Department, Egyptian Nuclear and Radiological Regulatory Authority (ENRRA), Cairo, Egypt \\ Nuclear Fuel Cycle Department, Egyptian Nuclear and Radiological Regulatory Authority (ENRRA), \\ Cairo, Egypt
}

Received $6^{\text {th }}$ July 2020 Accepted $24^{\text {th }}$ Sept. 2020

\begin{abstract}
Nuclear Knowledge Management (NKM) is an important pillar for the capacity building program of the regulatory body. It is handled as a long term investment that yields to excellence, effectiveness, and risk management of critical knowledge. Recently, the requirements for optimization and sustainability have led to a growing interest in business intelligence and knowledge management domains. In general, the nuclear industry is knowledge-based, as it relies on skilled workers and their competencies. Newcomer countries face common challenges related to brain drain, data overloads, and aging of the qualified workforce that could lead to loss of nuclear knowledge. As a result, the need to develop the regulatory practices to ensure that interested parties collaborate, share and manage the evolved nuclear knowledge is significant. This paper discusses the approach applied by the national regulatory body to develop the NKM program as a tool to support the regulatory decisions and maintain the public trust. It highlights the real practice to improve the interactions between knowledge, organization, culture, processes, and employee's competencies.
\end{abstract}

Keywords: Nuclear Knowledge Management, Regulatory Environment, Integrated Management System, Tacit Knowledge, organizational culture

\section{Introduction}

Knowledge Management (KM) is difficult to quantify. It contains elements of many disciplines of "hard" and "soft" sciences. KM practices can be found in several applications and industries [1]. Managing nuclear information is complex and requires financial, human, and organizational support. It covers long-term accumulation of knowledge in a wide area of sciences and engineering that encourages sharing and transfer among different generations. NKM will ensure that nuclear power plants are designed and operated safely and securely and that nuclear materials are used under effective regulatory control during the whole lifetime of the nuclear program. It can be defined as a systematic, integrated approach to identify, acquire, transform, develop, use, share, and preserve the nuclear knowledge, relevant to achieving specified objectives within the interested parties' organizations [2]. The success of NKM is driven by individual behaviors and highperformance information technology infrastructures. In general, the main barriers for knowledge sharing among the organization could be the unclear organization policy, the time pressure on individuals, and lack of skills. This is in addition to the fear of failure, blaming culture, weak managerial support, and lack of involvement in the decision-making process.

Corresponding author: raniagomaa@yahoo.com

DOI: 10.21608/ajnsa.2020.34271.1380

CScientific Information, Documentation and Publishing Office (SIDPO)-EAEA 
Early planning for knowledge management helps the organization to better acquire, store, and utilize its nuclear knowledge effectively. Section 2 of this study highlights the NKM common used models. Section 3 describes general method to build nuclear knowledge management program for the regulatory body. Section 4 focuses on the available innovative technology infrastructure. Section 5 shows the results ENRRA (the national regulator) as a case study of applying the proposed method.

\section{Knowledge Management Objectives and Requirements}

Knowledge in general is "information resident in people's minds, which is used for making decisions in unknown contexts" [3]. Therefore, knowledge must be in the mind of a worker or automated process to be productive, dormant, or transient. It can be stored in hard or electronic format for subsequent retrieval and application. It exists in two forms: explicit, and tacit. Explicit knowledge is easily codified and conveyed to others, it is expressed in writing documents, drawings, calculations, designs, databases, procedures, and manuals. On the contrary, tacit knowledge is more subjective, personal, and difficult to convey. Although it is more difficult to manage, tacit knowledge is the primary target of $\mathrm{KM}$ efforts, because it is the repository of the organization's strategic valuable knowledge [3]. NKM shall be established by the newcomer regulatory body to address knowledge as an added value chain as shown in Fig. (1). Inputs are needed resources, and requirements. Data represent the facts, concepts, or instructions. The information represents the data that is processed to be useful and provides answers to who, what, when, and where questions including the structure of information and its architecture, metadata, content quality, and more. Knowledge represents the application of data and information to provide answers to how and why questions. Wisdom is the capacity to understand and give meaning to data and information in the form of insight and experience. Wisdom and intelligence are reflected in the organization's actions, practices, and decisions.

KM's goal is to ensure easy and quick access to all information and to emphasize internal communication rather than just capturing and storing the knowledge [4]. Generally, the NKM program has the following objectives:

1. Knowledge Capture by creating NKM repositories that consist of structured documents with knowledge embedded in the form of reports, presentations, forms, records, articles, etc. that are properly stored and easily retrieved.

2. Knowledge Access Improvement by developing the related processes and procedures of knowledge transfer between individuals and organizations.

3. Working Environment Improvement by simplifying and rewarding knowledge capture, transfer, and use.

4. Knowledge Management as an Asset by including NKM targets in the annual reports as an asset that generates new income, increase safety budget, reduce non- compliances or minimize costs within the regulatory practices.

Several models have been developed to support the business to establish KM program. According to the SECI model shown in Fig.(2), the organizational knowledge creation shall be based on four pillars [5] as follows:

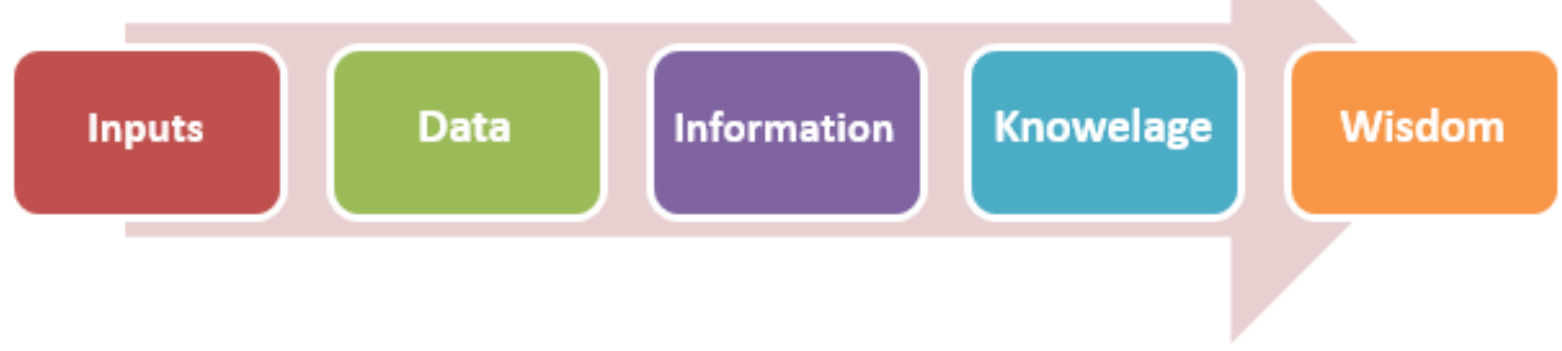

Fig. (1) Knowledge Management value chain 


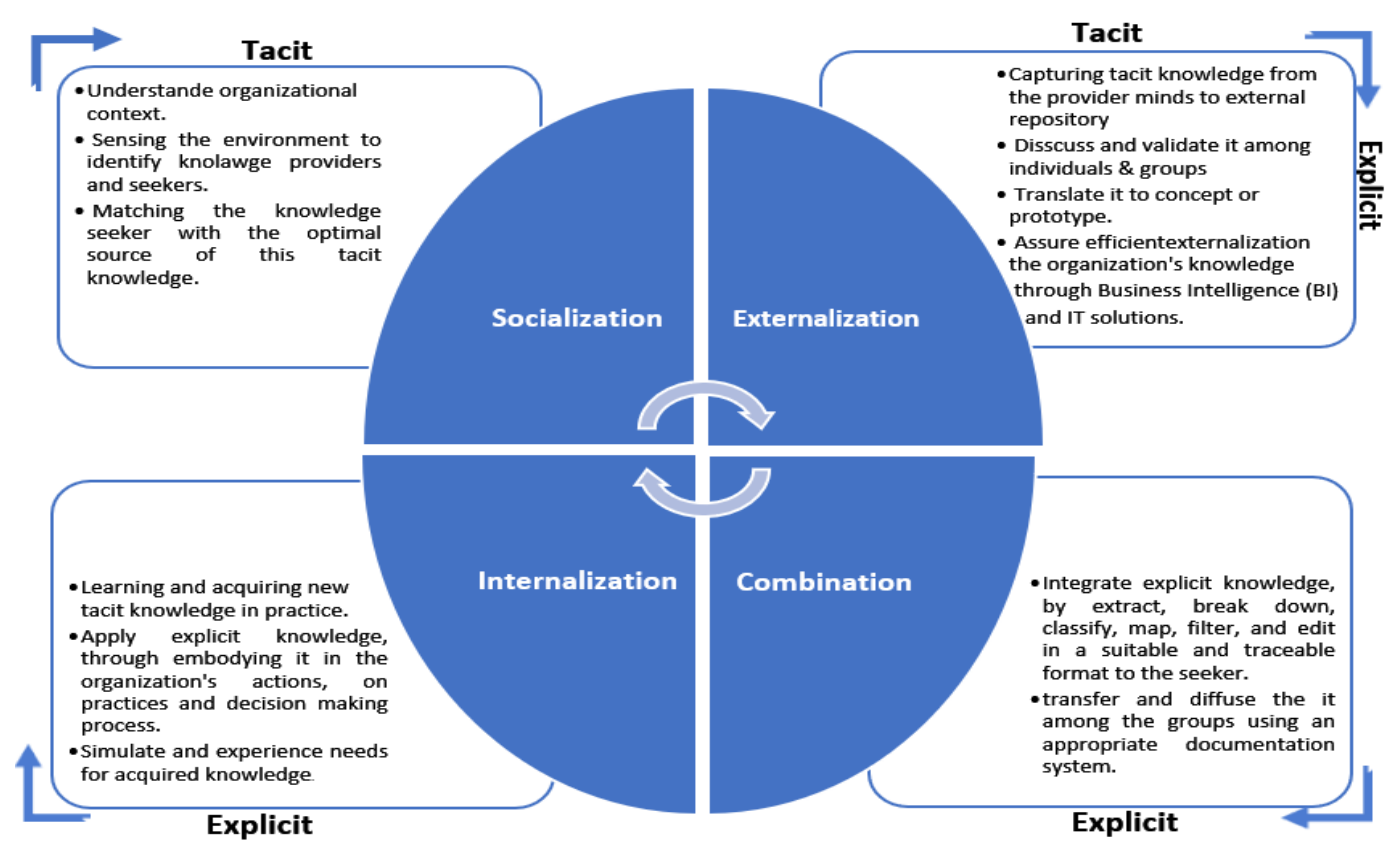

Fig. (2) SECI model for organizational knowledge creation [5]

\section{Nuclear Knowledge Management for a \\ Regulatory Body}

NKM should support the breakdown of the personal information preservation cycle to meet identified requirements for each regulatory practice. In fact, qualified employees with high level of competencies could not succeed to achieve the organization objectives if clear process, output and resources are not available. Also if the organizational culture is based on silos, blaming or disrespect, it will be impossible to build trust or progressive communication among the organization. On the other hand, relying on unqualified employees will have a remarkable effect on the organization culture, employee commitment, interested parties trust and finally hinder its performance. Fig,(3) shows the main enabling factors and elements for the successful NKMprogram of the regulatory body, which are as follow:

Questioning and Learning Attitude: This deals with organizational behavior aspects and social engineering. The role of learning is to manage information to build organizational learning and performance improvement. The key elements are learning communities, virtual teams, communication, and a culture of trust. The questioning attitude ensures a strong safety culture.

Nuclear Leadership: Leaders provide positive coaching when setting and communicating organizational values, ethics, and standards. They are responsible for strategic planning, systems thinking, and the best use of resources. They are vital to foster

cultural change, encourage open dialogue, rewards risk-taking, and knowledge sharing. They are role models that trigger effective career development among their colleagues and workers. Key elements for leadership are strategic planning, system thinking, decision making respected working environment, and organizational culture [2] [6].

Safety Culture: Nuclear knowledge is accumulated along with the nuclear project different phases. It will be split among several stakeholders (utility, regulators, vendors, R\&D centers, and technical support organizations), and they are expected to be closely connected in the complex flows of knowledge among them, which needs a strong commitment to the safety and security of cultures. The assessment of an organization's culture requires a methodology that uses a combination of tools. Key elements of 
safety culture are accountability, communication, learning, problem resolutions, and the environment of raising concerns.

Integrated Management System(IMS): It is the backbone of the work within the organization as it creates a systematic way to run regulatory processes, facilitate employee interactions, and support effective regulatory practices. The nuclear industry emphasizes the management system as an important contributor to safety and quality. Project management, quality assurance, and human resource management are integrated to connect people's activities and knowledge. The key elements of IMS are strategies, organizational structures, policies, processes, procedures, control measures, performance indicators, communication, and continuous improvement. [2]

Technology infrastructure: It deals with the various information technologies peculiar to supporting and/or enabling KM strategies and operations. It should be of high quality, capable of expanding based on the needs, compliant with industry standards. Also, it needs to optimize the use of existing resources, and encompass all inputs and business processes of the organization. The key elements of it are communication, virtual teams, electronic mail, intranet, internet, data warehousing, and decision support systems [7]. This area is discussed in the next section in detail.

Human Resources Development: It deals with the management of employee knowledge, skills, and attitudes to improve their fitness for duty. Also, it covers employee engagement, recognizing and rewarding individuals to ensure effective teamwork both internal to the organization and with suppliers and contractors. Key HR factors are workforce planning, recruitments, education \& training, and team development [7]. It requires strong partnerships between the nuclear industry with schools and universities to create interest in science, technology, engineering, and nuclear careers. Career development is also important to show individuals how they can progress through the organization.

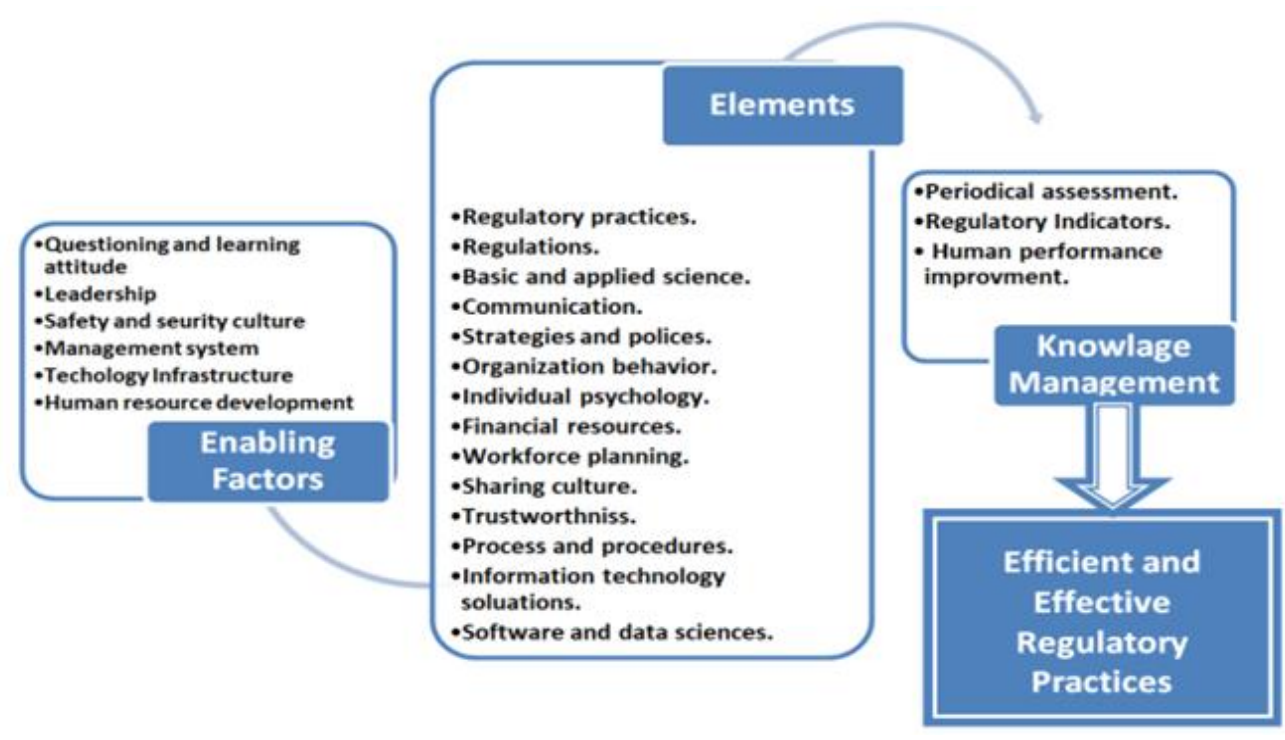

FIG. (3) Roadmap for the knowledge management for regulatory body 


\section{Innovative Technology Infrastructure}

The KM system shall support a large number of users, analysts, data storage, and database. The technology should be able to handle the knowledge of any form, including different subjects, structures, and media, learn about users and related processed knowledge, and use appropriate communication protocols. If it deals with many requests in a particular field, it should be interactive and learn how to assist users in more depth. The IT solution should intelligently deduce the user's needs and suggest associated knowledge. The standardization of communication and access provided by the technology has created an enormous global market for KM systems [8] [9]. The main technical requirements for a successful IT solution are represented in Fig.(4)

However due to the massive change in ICT technologies and data analytics, the technology is changing the ways to perform work, hence the business processes and models of organizations will need to be re-evaluated and adjusted soon. Big data analytics is one of the newest technologies that have been designed to utilize information assets and support the decision making process. However, the technology still faces some challenges that could limit its use in the nuclear industry [10]. On top of those challenges is the cybersecurity threat which evolves rapidly. As a result, new tools and solutions could be deployed on the system to reduce the risk and address the cyber-security threat. They need to develop a proactive approach where related threats could be easily identified and treated before an attacker can cause a negative impact. Big data technology could have a great impact on the performance improvement of the manufacturing and operation processes of Structure, Systems, and Components (SSCs) of nuclear power plants. Knowledge generation, transfer, and application are realized through integrated automatic design and analysis platforms. As the 3D visible design, digital dynamic performance $\mathrm{V} \& \mathrm{~V}$, building information modeling (BIM) technology, online monitoring, and configuration management. Data centers could facilitate knowledge handover among the stakeholders. For example, some vendors deliver $3 \mathrm{D}$ models and engineering parameters to those data centers after NPP design is accomplished [11].

The entire knowledge management system is accessed through a unified interface. Several information management technologies could be used; web content management $(\mathrm{CM})$, document management $(\mathrm{DM})$, records management (RM), digital asset management (DAM), learning content management (LCM), 3-D modeling, digitization, and more [12].

\section{National Regulatory Body Practice}

Nuclear law 7/ 2010 established the Egyptian Nuclear and Radiological Regulatory Authority (ENRRA) as an independent regulator to control nuclear and radiological activities to protect human, property, and environment from the risks of exposure to ionizing radiation. ENRRA scope of responsibilities covers; Safety, Security, Safeguard, and Emergencies.

The regulatory oversight is conducted through inspection to assess the performance of licensee and applicants. ENRRA treats information as a key element for making regulatory decisions. ENRRA employees access knowledge via various sources from staff, experience, internet, data stores, files, and desktops. The training center plays an important role to transfer the knowledge among employees to perform their regulatory activities. ENRRA builds strong communication lines with universities and $R \& D$ centers on the national level together with cooperation programs on the international level through to provided up-to-date resources needed for continuous improvement of regulatory practices.

ENRRA defines clear measurable objectives for all its processes, and provide the needed resources to enhance the employee engagement and commitment and ensure that wisdom are reflected in all its regulatory decisions. Moreover, it gives attention to the interaction between all elements and adopt the clear roadmap to build its NKM program based on the six enabling factors proposed earlier in section 3 .

\section{Integrated management system}

The management system of ENRRA establishes a single controlled environment for the organization's operation binding rules for all staff. It is based on the principles set in forth of the IAEA requirements, and ISO 9001:2015. [13] It acts as an efficient and effective tool to meet strategic goals and satisfy national needs and expectations, through: 
Integrating all activities, objectives, and processes into one system,

* Providing clear authorities \& responsibilities,

* Allowing engagement of interested parties,

* Optimizing the use of financial and HR employees,

\# Removing barriers between units,

* Facilitating internal sharing of information,

\# identifying needs for improvement,

* Enabling consistency in regulatory practice,

* Providing tools for monitoring the organization performance,

* Increasing the effectiveness and efficiency

* Enhancing public confidence,

* Training ENRRA staff on MS.

* Developing a strong safety culture and enhancing leadership skills

It is based on the process approach, classified into process, sub-process, and procedure. The process map shown in Fig.(5) includes the core, management, and support process.
ENRRA defines assembly of characteristics among employee which establishes an overriding priority, and ensure that safety issues receive the attention warranted by their significance. Three classes of attributes are defined; individual commitment to safety, organization commitment to safety, and management system described in 5.1. ENRRA is working on many characteristics that belong to each class since 2012, especially with IMS, communications, and learning. ENRRA Senior Managers ensure that a well-developed knowledge management system is to stimulate the questioning and learning attitude by providing the needed knowledge.

ENRRA uses surveys and feedback reporting to monitor progress in this area. Table (1) shows the results of feedback reports for five internal and external training programs during the assessment period. Fig. (6) reflects a notable increase in the learning and questioning attitude since 2014, even that it is fluctuating, but it is a good indication of the strength of safety culture.

Safety culture
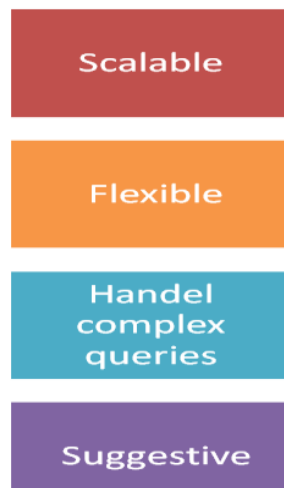
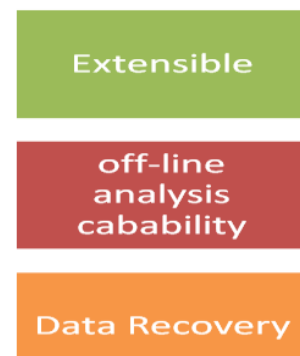

Robsut and Reliable

\section{Compliant \\ with industrial \\ standards}

Fast and easy deployment

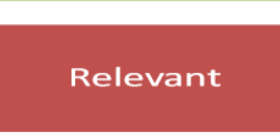

Preventive Maintenance
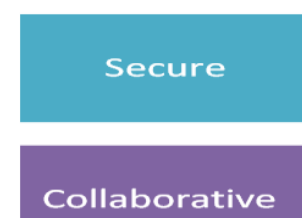

Collaborative

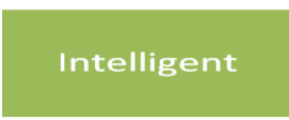

Friendly User Interface

Fig. (4) Requirements for an IT solution of KM

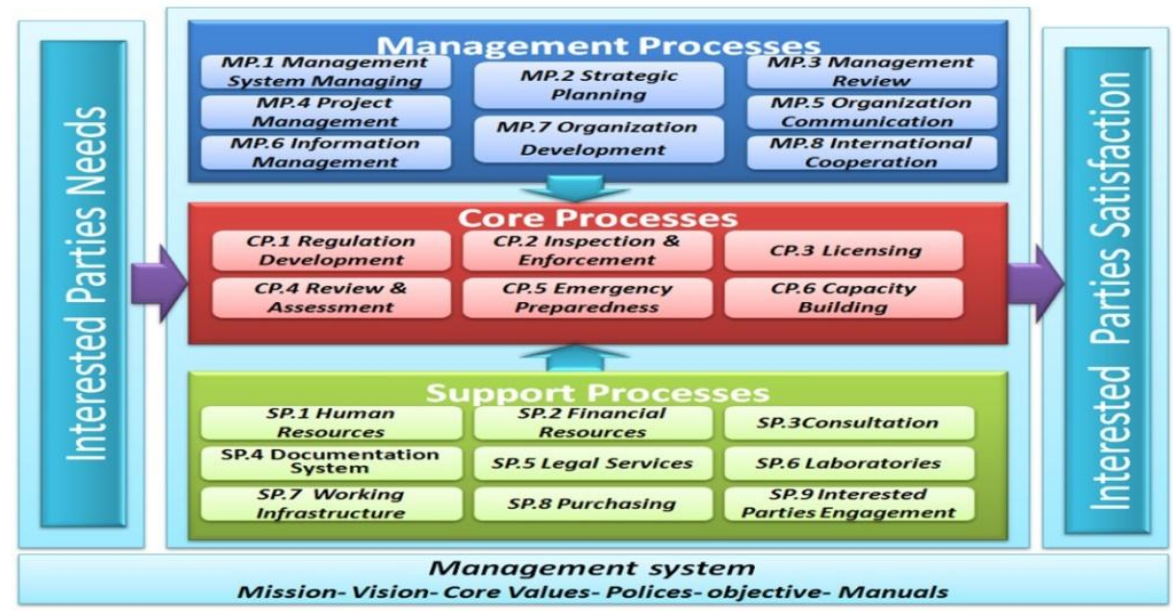

Fig. (5) ENRRA integrated management system process map 


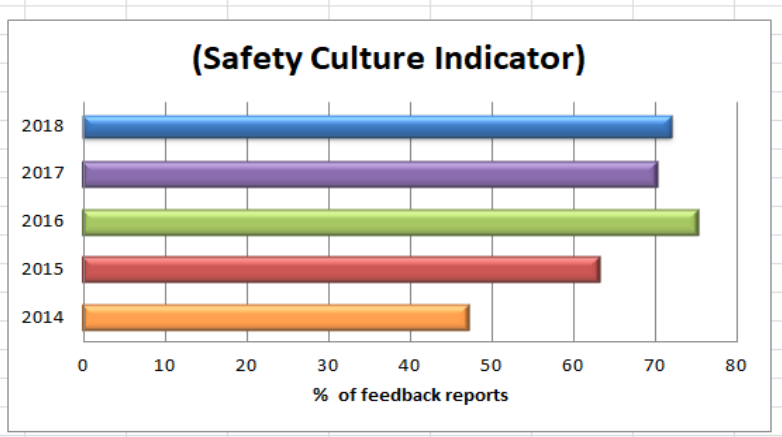

Fig. (6) Progress of Safety Culture

Table 1 Sample of the training record for safety culture assessment

\begin{tabular}{l|r|r|r|r|r|}
\cline { 2 - 6 } Year & 2014 & 2015 & 2016 & 2017 & 2018 \\
\hline $\begin{array}{l}\text { No. of ENRRA } \\
\text { Participants }\end{array}$ & 53 & 60 & 82 & 36 & 28 \\
\hline $\begin{array}{l}\text { Returned } \\
\begin{array}{l}\text { Feedback } \\
\text { Reports }\end{array}\end{array}$ & 25 & 38 & 63 & 25 & 20 \\
\cline { 2 - 6 }
\end{tabular}

\section{Capacity Building}

Core processes are related to ENRRA's main functions. Capacity building is defined as a core process and as a strategic goal for the early stages based on four elements;

HRD through requalification for available staff and the recruitment of new staff.

Education and training through basic, specific, and refreshing training programs.

Knowledge management as per coaching, mentoring and periodical meeting.

Knowledge networks through cooperation with different networks (GNSSN, ANNuR, and FNRBA)

The Systematic Approach of Training (SAT) is recognized by the interested parties as one of the best models for training in the regulatory body. It is based on the Competence Needs Assessment (CNA) shown in Fig. (7). It includes the training needs assessments gap analysis, planning, job description, education, qualification, training, and recruitment [14].

Training programs are planned based on the planned career development of individuals. Training needs of the staff are based on selfassessment of the individual competencies and identified unit training plans integrated into the annual training plan. ENRRA performs selfassessment training based on IAEA Model as an input to the staffing plan and the annual training programs [15]. Three competency categories are identified; senior, intermediate, and junior. The education and training program covers three training levels:

- Basic Level: it represents the in-house basic training aligned with the IAEA approach. The course develops the competencies on the basic safety concepts and knowledge, it includes 24 Modules. It covers reactor technology, nuclear safety, safety assessment, radiation safety, physical protection, etc.). The first"BP01: Basic Professional training program on nuclear safety" starts in August 2016 for the newly recruited staff.

Specific level: ENRRA has developed through multi-directional international cooperation programs to expose the staff to different international practices, including:

- International Atomic Energy Agency.

- European Commission.

- Korean Institute of Nuclear Safety (KINS).

- Federal Environmental, Industrial and Nuclear Supervision Services of Russia (RTN);

Advanced level: ENRRA develops and implements this type of training through bilateral agreements with the regulatory bodies and proposed vendor countries for specific technology under the ENRRA regulatory control. The training takes place in different forms; workshops, technical meetings, on job training (OJT's), expert missions, and others. Fig. (8) shows the number of trained staff via specific and advanced training from 2013 to 2018. More efforts are still needed for advanced courses.

On the national level, the Supreme Committee for Training and Human Resources Development for the nuclear power plants established to integrate HRD 
strategy with the overall program The committee is responsible for developing strategies for education and training, evaluating the cooperation with the international organization, and maximizing the use of national available competencies in universities, and research centers. However, each organization develops its own plan. The Employee Affairs regulation issued by the Prime Minister by Decree No. 348/2019 regulates the HRD plan of ENRRA including positions, recruitment process, human resources and training committee, rewarding systems, and the salary policy. Generally, workforce planning highlights the needs in term of the size, type, and quality of the required workforce to achieve the objectives. It identifies what mix of experience and competencies are expected. For new build projects, IAEA recommends the Nuclear Power Human requirements and milestones.

Resources tool (NPHR) [16], for workforce planning on the national level. It is suitable at phase one to indicate the number of staff needed for the different stakeholders (Operator, regulator, universities ...etc.). However, it needs to be customized on the country education system and consider available pipelines for both vocational, under and post-graduate education. Other available tools for HRD as OCTOPUS act as project management tools that could be applied for managing the needed competencies for the construction of NPP. It does not consider other workloads by the regulatory body that could supervise other nuclear and radiological facilities or activities.
Process 1

Developing competence profiles
Process 2

Competence gap analysis
Process 3

Periodic review

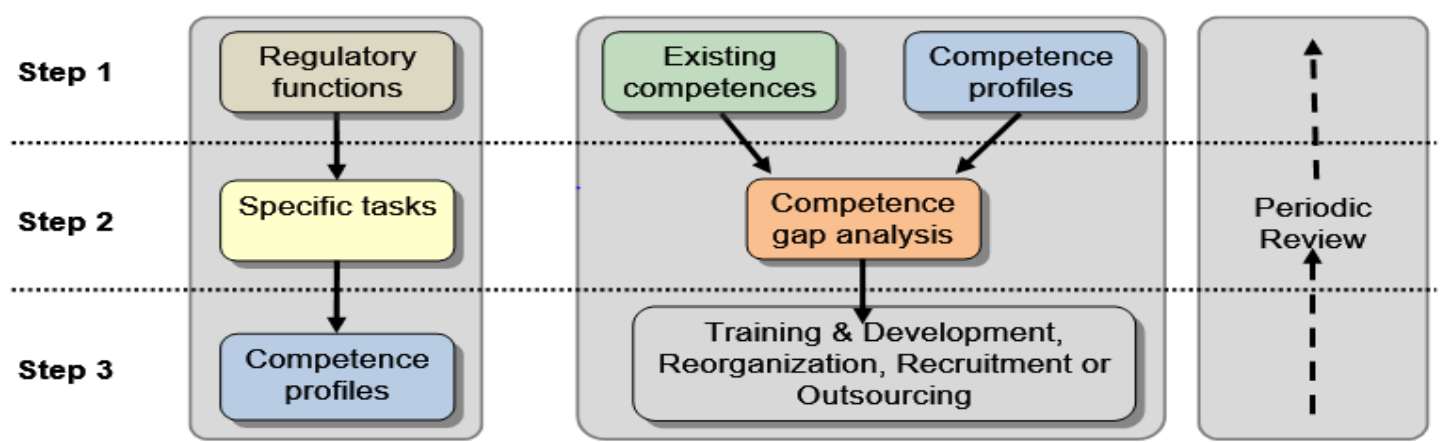

Fig. (7) Step based competence needs assessment

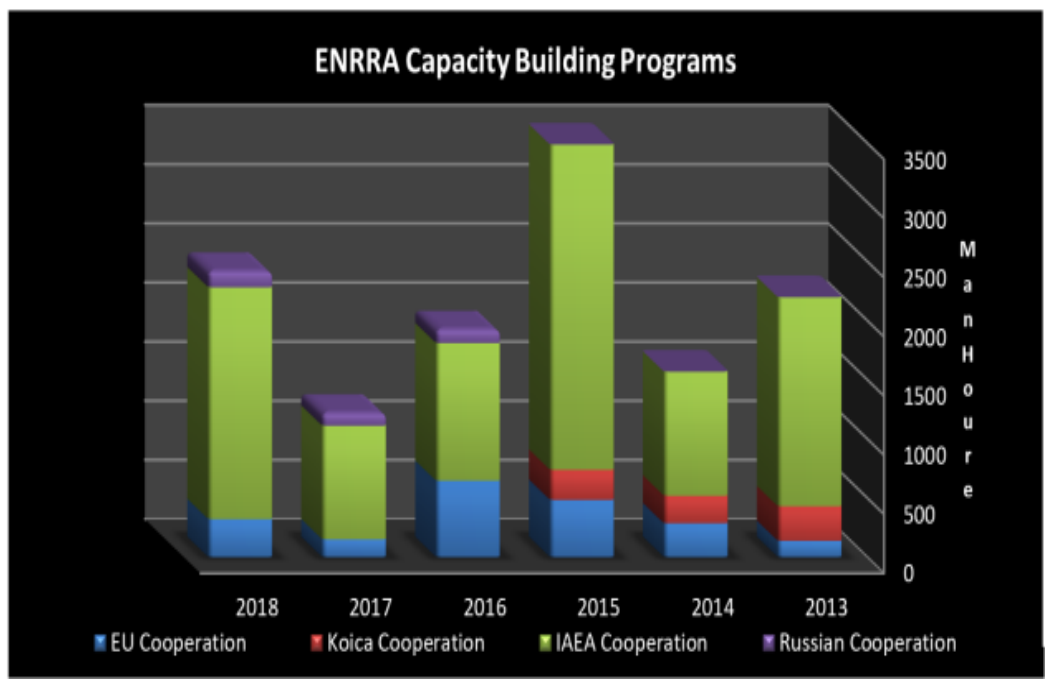

FIG.(8) The number of trained staff via international cooperation. 


\section{Conclusion}

The primary role of $\mathrm{KM}$ is to connect knowledge nodes effectively, both the knowledge providers and seekers. NKM provides a means of capturing and storing valuable knowledge and transferring it to the appropriate individuals. Management system and capacity building elements are effective tools to ensure that the regulatory body maintains a qualified workforce and preserve its critical knowledge. ENRRA is working to build innovative nuclear knowledge management with an advanced IT infrastructure to tackle the challenges related to national projects. Multidimensional technical cooperation plays an important role to improve the national regulatory competencies for authorization, developing regulations, review and assessment, and inspection. ENRRA invests in the learning environments during the last six years which is reflected positively in the change of the organizational culture. More efforts are still needed to attract, and retain a high-quality nuclear workforce, develop teams and leaders, and sustain the accumulated nuclear knowledge gained during the lifetime of the nuclear power plant program.

\section{References}

1. Alavi, M. and Leidner, D., Knowledge Management systems: issues, challenges, and benefits. Communications of the Association for Information Systems. 1(7), pp.2-36, 1999.

2. International atomic energy agency, Knowledge Management, and Its Implementation in Nuclear Organizations, NGT-6.10, 2016.

3. Carroll, B.Comparative Analysis of Methods and Tools for Nuclear Knowledge Preservation, 2006.

4. Weber, F., Wunram, M., Kemp, J., Pudlatz, M., Bredehorst, B, Towards common approaches and standards for knowledge management in Europe, Proceedings of UNICOM Seminar towards Common Approaches \& Standards in KM, 2002

5. Nonaka, I., Toyama, R. and Konno, N. 'SECI, $\mathrm{Ba}$, and leadership: a unified model of dynamic knowledge creation'. Long Range Planning, 33, pp 5-34, 2000.

6. International atomic energy agency, Knowledge Management for Nuclear Industry Operating Organizations. TECDOC1510, IAEA, Vienna, 2006.
7. Kosilov, A., Pasztory, Z., The development of KM portals for nuclear power plants. Int. J. Nucl. Knowl. Manage. 3 (4), 348-354, 2009

8. Argote, L. and Ingram, P. Knowledge transfer: a basis for competitive advantage in a firm. Organizational Behavior and Human Decision Processes. 82(1), pp. 150-169, 2000.

9. D. Cameron, Big Data in Exploration and Production: Silicon Snake-Oil, Magic Bullet, or Useful Tool?, In SPE Intelligent Energy Conference \& Exhibition, Society of Petroleum Engineers, 2014.

10. J. R. Alam, A. Sajid, R. Talib, and M. Niaz, A Review on the Role of Big Data in Business, 2014.

11. Kosilov, A., Yanev, Y., Mazour, T, Knowledge management for new nuclear power infrastructure. Int. J. Nucl. Knowl. Manage. 3 (4), 431-440., 2006

12. Mentzas, G., Apostolou, D., Abecker, A., Young, R., Knowledge Asset Management. Beyond the Process-centred and Productcentred Approaches, 2003.

13. International atomic energy agency, Leadership, and Management for Safety, GSR Part 2, IAEA, 2016.

14. International atomic energy agency, Managing regulatory body competence, Safety Report Series 79, 2013

15. International atomic energy agency, Methodology for the Systematic Assessment of the Regulatory Competence Needs (SARCoN) for Regulatory Bodies of Nuclear Installations, TECDOC 1757, 2014

16. International atomic energy agency, Workforce planning for new power plant programs, NGT-3.10, 2011. 